\title{
Pós-graduação e Residência Multiprofissional em Saúde HC-UFG: a produção do Serviço Social
}

\author{
Denise Carmen Andrade Neves \\ Pontifícia Universidade Católica de Goiás (PUC/GO)
}

Tereza Cristina Pires Favaro

Universidade Federal de Goiás (UFG)

\author{
Carla Ágda Gonçalves \\ Universidade Federal de Goiás (UFG)
}

Pós-graduação e Residência Multiprofissional em Saúde HC-UFG: a produção do Serviço Social Resumo: O objetivo deste ensaio é discutir a produção do Serviço Social em residência multiprofissional em saúde a partir, especificamente, do estudo dos Trabalhos de Conclusão de Curso (TCCs) apresentados pelas residentes egressas do Programa de Residência Multiprofissional e em Área de Saúde do Hospital das Clínicas da Universidade Federal de Goiás/EBSERH entre os anos de 2012 e 2016.

Palavras-chave: Serviço Social. Pós-graduação. Residência Multiprofissional. Saúde.

Graduate Studies and Multiprofessional Residency in Healthcare at HC-UFG: the production of Social Work

Abstract: The purpose of this paper is to discuss the production of Social Work in Multiprofessional Residency in Health; particularly, the study of Final Term Papers (TCCs) submitted by residents that have completed the Multiprofessional Residency in Health Program of the Clinical Hospital of the Federal University of Goiás/EBSERH between 2012 and 2016.

Keywords: Social Work. Graduate Studies. Multiprofessional Residency. Health. 


\section{Introdução}

O presente artigo é parte de estudos, pesquisas e atuações profissionais empreendidos pelas autoras frente à experiência acumulada junto ao Programa de Residência Multiprofissional em Saúde do Hospital das Clínicas da Universidade Federal de Goiás (HC-UFG/EBSERH). Constitui objetivo central deste artigo identificar e analisar os Trabalhos de Conclusão de Curso (TCCs), apresentados e defendidos pelas residentes egressas do Programa de Residência Multiprofissional em Saúde do HC-UFG/EBSERH, no eixo específico Serviço Social, entre os anos de 2012 e 2016. Esse objetivo adveio de indagações das autoras sobre a produção em Serviço Social na realidade do programa de Residência Multiprofissional em Saúde do HC-UFG/EBSERH, bem como os direcionamentos assumidos pelos trabalhos de conclusão de curso das egressas residentes em Serviço Social. Diante desse caminho percorrido com a problematização, construímos a pergunta norteadora do artigo, qual seja: quais os direcionamentos advindos das produções dos trabalhos de conclusão de curso defendidos pelas egressas em Serviço Social?

Do ponto de vista metodológico, trata-se de uma pesquisa qualitativa, recorrendo a alguns dados quantitativos, abrangendo a pesquisa bibliográfica e pesquisa documental a partir da metodologia do estado da arte. Segundo Ferreira (2002, p. 258), o estado da arte: "parece trazer em comum o desafio de mapear e de discutir uma certa produção acadêmica em diferentes campos de conhecimento [...] também são conhecidos por realizarem uma metodologia de caráter inventariante e descritivo da produção acadêmica e científica sobre o tema". Para tanto, toma-se como fonte básica de referência para identificação e análise a utilização de catálogos construídos pelas autoras, posto que no Programa não existe essa construção prévia. Em um primeiro momento, reuniu-se a produção dos TCCs apresentados e defendidos no Programa de Residência Multiprofissional, eixo específico Serviço Social; mapeando o quantitativo de 15 trabalhos entre o período de 2012 até 2016.

Em um segundo momento, fez-se inventário dessa produção a partir de alguns eixos, quais sejam: ano de defesa; objeto do trabalho (se abordava a atuação do Serviço Social e/ou seu trabalho no HC-UFG/EBSERH); utilização de aporte teóricos associados à bibliografia básica da profissão; método utilizado; procedimentos de pesquisa; e relação de coerência entre a análise e o referencial utilizado.

Para tanto, neste artigo, optou-se, inicialmente, por evidenciar breves considerações acerca dos aspectos sócio-históricos e políticos que possibilitaram a implementação do Programa de Residência Multiprofissional em Saúde, tanto na realidade brasileira, como na particularidade do HC-UFG/EBSERH, explicitando os desafios e possibilidades que se apresentam nos TCCs da Residência Multiprofissional em Saúde, Eixo específico Serviço Social, do HC-UFG/EBSERH.

\section{Residência multiprofissional e sua particularidade no HC-UFG/EBSERH}

A Residência multiprofissional foi pensada desde a década de 1970 quando se deu a regulamentação das residências médicas, contudo somente trinta anos depois passaram a ser fomentadas iniciativas de formação de recursos humanos para o SUS, sobretudo com o Projeto de Reforço e Reorganização do Sistema Único de Saúde (Reforsus) (MENDES, 2013). A articulação e o trabalho junto às entidades e instituições representativas da área da saúde desde 2005, resultaram na regulamentação das Residências Multiprofissionais com a promulgação da Lei 11.129 de 2005 (BRASIL, 2005), como alternativa na superação da formação profissional prevalente nas diferentes áreas da saúde centrada no modelo biomédico, fragmentado e especializado. Condição que enfraquece a compreensão dos determinantes sociais e a intervenção sobre os processos saúdedoença da população. Compreende-se que, nesta perspectiva, a fragmentação se apresenta como limite à integralidade, ao reforçar uma prática acrítica e incapaz de responder as necessidades da saúde.

Cabe destacar, que o Programa de Residência Multiprofissional em Saúde se estruturou teórica e metodologicamente em consonância com as diretrizes da Política de Educação Permanente para o Sistema Único de Saúde (SUS), almejando uma aprendizagem em equipe multiprofissional inserida na realidade dos serviços de saúde. A proposta é contribuir na formação de categorias profissionais reconhecidas pela Resolução do Conselho Nacional de Saúde (n. 287/1998), e qualificá-las para o desempenho de suas atividades com competências técnica, política e ética. O objetivo geral do programa é a atuação na atenção básica, de cuidado integral à saúde das pessoas, famílias e comunidades, além da gestão do trabalho com enfoque multiprofissional que proporcione o desenvolvimento do trabalho em equipe interdisciplinar, buscando melhoria da saúde e da qualidade de vida da população.

Mendes (2013, p.193) enfatiza que: 
A residência multi traz muitas inovações [...] Além de seu recorte interdisciplinar e da influência dos movimentos sociais na construção inicial da política, essa residência apresenta desde o início o compromisso com ensino em serviço, em contraposição político-pedagógica à perspectiva de treinamento em serviço, que privilegia o aprendizado pela prática sem a obrigatoriedade de uma reflexão teórica.

Tal formação é regulamentada pela Portaria n. 03/2010, que define o percentual de carga horária das atividades teórico, teórico-práticas e práticas; enfatizando a necessidade de um Trabalho de Conclusão de Curso de Residência como exigência para a conclusão, apresentado em forma de artigo ou de trabalho monográfico (MENDES, 2013).

Na particularidade do HC-UFG/EBSERH, a Residência Multiprofissional em Saúde foi implantada em março de 2010, nas áreas de Serviço Social, Enfermagem, Fonoaudiologia, Odontologia, Psicologia, Nutrição, Fisioterapia, Farmácia e Biomedicina. O programa é realizado - seguindo as regulamentações nacionais - na forma de educação em serviço, tem a duração de 24 meses, ou 5.760 horas de duração, sendo majoritariamente realizado dentro do HC/UFG, envolve ainda unidades de saúde da rede SUS, vinculadas ao município e estado. As equipes são integradas à dinâmica do serviço, propiciando uma imersão local; em que 80\% da carga horária é cumprida na prática e $20 \%$ corresponde à carga-horária teórica, com aulas e discussões sobre a política de saúde, a área de concentração que o residente sairá especialista e o eixo específico relacionado à profissão do mesmo. Assim, interessa realçar que a Residência se fundamenta no processo de ensino-aprendizagem baseado no movimento dialético entre as ações cotidianas no espaço da prática profissional articulado com a teorização e a reflexão crítica; sempre considerando as necessidades de aprendizagem de cada residente, na busca de informações, identificação de evidências a serem investigadas, para cuidado e aplicação do conhecimento.

No que tange às particularidades desse processo para o Serviço Social destaca-se que todo o agir Profissional/Residente de Serviço Social deve estar em consonância com o trabalho desenvolvido pelos assistentes sociais do Hospital das Clínicas/UFG, a luz do Projeto Ético Político do Serviço Social construído coletivamente pela categoria, norteado no campo dos direitos e da proteção social, com vistas à humanização da assistência, à defesa dos interesses coletivos. Para tanto, o assistente social possui um lugar estratégico na área da saúde, com uma leitura crítica do contexto socioeconômico no qual os usuários estão inseridos, fornecendo elementos importantes para compreensão dos aspectos sociais, econômicos e culturais que influenciam no processo saúde-doença, mormente numa conjuntura de desafios e entraves, posto que ele deva identificar as mediações e possibilidades dadas pela realidade social, envolvendo as demandas institucionais, profissionais e da população usuária dos serviços de saúde, tendo em vista a sua participação como sujeito ao acessar direitos e serviços com vistas à qualidade de vida no processo de saúde e doença. Destaca-se que a capacitação profissional pela residência é uma estratégia já legitimada no decorrer da história do processo de formação profissional para a área da saúde. Da mesma forma refere-se à abordagem interdisciplinar como meio de superar a fragmentação do saber. De acordo com Vasconcelos (2003), a atuação interdisciplinar na área da saúde contribui para a construção de uma consciência sanitária que busque extrapolar as ações na prevenção e combate à doença, ao se dirigir essas ações no processo de elevação das condições materiais e vida da população.

A intrínseca característica da interdisciplinaridade confere um caráter inovador ao Programa de Residência Multiprofissional em Saúde, e assegura ao Serviço Social um importante espaço de atuação profissional, como possibilidade de alterar o modelo hegemônico atual, centrado no saber médico, a partir do conceito ampliado de saúde, bem como os fatores que intervém no processo saúde-doença. Nesse sentido, entender o potencial e os limites de contribuição do Serviço Social impõe o desafio de romper com as práticas conservadoras, cabendo ao profissional identificar, planejar e desenvolver ações que interfiram nos determinantes sociais do processo saúdedoença de maneira a contribuir para ampliar e facilitar o acesso dos usuários aos seus direitos.

O processo político-pedagógico da Residência Multiprofissional traz a concepção de práxis entendida aqui como exigência da atividade científica que estabelece o contato entre os profissionais e a população para possibilitar, politicamente, o avanço de uma concepção de mundo coletiva. Trata-se de uma prática social dialeticamente concebida, que constrói, em parceria com os sujeitos, a população usuária, mediações consistentes articuladas às práticas concretas das classes sociais. Para tanto, a Residência Multiprofisssional em saúde objetiva construir e reafirmar competências dos profissionais que atuam na área para o cuidado em saúde, por meio de ações efetivamente interdisciplinares tendo como eixo orientador os princípios e diretrizes do SUS e as necessidades locais e regionais. Segundo Mendes e Silva (2013, p. 55), "a interdisciplinaridade pressupõe que cada uma das áreas exerça seu potencial de contribuição preservando a integridade de seus métodos e conceitos e, nesse sentido, requer o respeito a autonomia e à criatividade de cada uma das profissões envolvidas, cujo relacionamento deve tender a horizontalidade".

Mesmo diante das antinomias expressas na processualidade da Residência Multiprofissional, ressalta-se que esse objetivo tem intrínseca relação com a direção social e política consolidada pelo projeto ético-político 
profissional, pois visa uma rigorosa formação teórico-metodológica ao priorizar a leitura teórico-crítica do atual processo de desenvolvimento capitalista e suas particularidades no Brasil, e no campo das políticas públicas, bem como seus rebatimentos no exercício profissional; e uma estreita articulação com os movimentos, entidades e forças políticas dos trabalhadores em defesa dos direitos humanos e sociais.

Em relação à atuação do Serviço Social no HC-UFG/EBSERH, ela é pautada em demandas específicas que influenciam diretamente na problemática apresentada pelos usuários ou familiares, e que diz respeito à área das necessidades humanas e sociais. As atividades desenvolvidas cotidianamente neste hospital, muitas vezes expressam um fazer profissional não reflexivo, preocupado em dar resposta à demanda, em viabilizar o acesso da população ao atendimento, buscando, assim, minimizar as deficiências das políticas públicas, em especial a de saúde, frente à grande demanda. Em face disso, o cenário posto para o assistente social na instituição é o contínuo desafio para o atendimento à demanda, em que as ações assumem um caráter de providências e urgências na sua operacionalização, aspectos que demarcam ao assistente social, a imperiosa prontidão para agir, reforçando o fazer profissional permeado pelo ativismo, impedindo a avaliação e a reflexão da prática, acarretando um comprometimento da atuação profissional, e, em alguns momentos, submetendo o mesmo a ter suas ações definidas por outras instâncias.

A residência, nesse sentido, vem contribuindo para que o Serviço Social do HC/UFG ultrapasse o limite assistencial, articulando-se o seu exercício profissional às áreas de ensino, pesquisa e extensão. Partindo desta compreensão, o assistente social é estimulado a se capacitar a fim de possibilitar uma prática reflexiva e crítica que coadune com efetivação dos princípios e diretrizes do SUS em consonância com o projeto de profissão, no sentido da construção de estratégias coletivas de enfrentamento para as expressões da questão social presentes na esfera da saúde. Uma das decorrências desse processo pode ser evidenciada, a partir de 2010, com a elevação da titulação das assistentes sociais do HC, seis profissionais concluíram a pós-graduação em nível de mestrado e duas foram inseridas neste ano ${ }^{1}$.

Destaca-se que, atualmente o Serviço Social conta com um total de dezesseis profissionais, sendo que dessas, três são doutoras e quatro são mestres, todas com atuação no Programa de Residência Multiprofissional.

\section{A produção em Serviço Social na Residência Multiprofissional do HC/UFG: as marcas expressas nos TCCs}

A pesquisa do Estado da Arte utilizou como fonte quinze TCCs entregues no Programa de Residênciaª até novembro de 2016. O conjunto das pesquisas desenvolvidas por este programa constitui-se em um significativo material de investigação e registro do que pode ser alcançado pela residência multiprofissional em saúde e, sobretudo, de visibilidade sobre o trabalho do Serviço Social HC-UFG/EBSERH e da inserção do assistente social na equipe multiprofissional de saúde.

Ao catalogar os trabalhos de conclusão de curso da Residência, foi possível identificar algumas convergências e divergências, o que nos leva a identificar marcas particulares advindas da própria configuração da Residência Multiprofissional em Saúde no HC/UFG. Enquanto uma das marcas significativas de convergência se pode apontar a elaboração de artigo como forma de explicitar a conclusão da residência, posto que, como evidenciado anteriormente, a portaria 03/2010 abre a opção tanto ao artigo quanto à monografia. Não é possível, com isso, aferir conclusões mais específicas, pelos limites da metodologia do Estado da Arte, na medida em que as informações não estão dispostas para tal identificação; cabendo-nos sinalizar apenas enquanto uma possibilidade de pesquisa de campo.

No que tange às divergências, elas assumem configurações diferenciadas em cada trabalho, com feições particulares e, em alguns casos, mais gerais perpassando questões constitutivas e constituintes inseridas na dimensão teórico-metodológica assumida pelo residente. Nesse sentido, optou-se por apresentar e tecer as devidas considerações frente aos eixos apresentados e explicitados anteriormente na introdução desse artigo.

Sete trabalhos tomaram como referência objetos relacionados aos espaços sócio-ocupacionais nos quais exerceram suas atividades (Ambulatórios, Clínicas e Pronto Socorro), abordando temáticas como: demandas previdenciárias dos usuários, reflexões sobre os aspectos legais e análise do perfil dos usuários. É importante ressaltar que três desses estudos discutem diretamente a prática profissional do assistente social.

Nesse sentido, ao construir um inventário mais específico sobre esses artigos, ressalta-se que o primeiro deles aborda os aspectos legais que perpassam o cotidiano do assistente social enfatizando a necessidade de subsidiar atuação profissional nos referenciais teóricos da profissão, referindo-se à prática no HC. Analisa, ainda, o objeto a partir da relação entre saúde, questão social e sociedade capitalista, bem como o serviço social no âmbito das relações sociais. 
Já o segundo artigo discute a intersetorialidade e a atuação do Serviço Social no Pronto Socorro - HC. O estudo parte de uma reflexão crítica da intersetorialidade apontando-a como uma estratégia para responder às necessidades da população, mas, ao mesmo tempo reconhece seus limites e os impactos disso para a atuação profissional.

A partir das atribuições do assistente social-HC, o terceiro artigo busca construir uma reflexão crítica do exercício profissional voltado ao atendimento das demandas sociais da população. Destaca a importância da ação profissional sustentada pelas dimensões constitutivas da profissão, com destaque à competência teóricometodológica e ético-política, com intuito de resguardar o acesso dos usuários às ações e serviços de saúde, bem como de não assumir atribuições delegadas por outros profissionais, que não são de sua competência.

Os demais estudos trataram de temas que tangenciam o Serviço Social. Dois tratam da Política Nacional de Humanização, um deles relacionando-a a violência institucional e outro destacando sua importância perante o desmonte da saúde nas últimas décadas; um analisa a interdisciplinaridade e outro a intersetorialidade na residência; o processo de adoecimento e a relação com a proteção previdenciária foi discutido por um trabalho; outro, ainda, analisa o processo de judicialização da saúde; e um particulariza para a garantia do direito à educação à criança com doença crônica.

Depreende-se como significativo, no processo de educação em serviço, os residentes egressos discutirem tanto seus cenários de prática, como a política de saúde em si, pois possibilita revisitar os espaços sócioocupacionais em que estão inseridos os assistentes sociais nos hospitais, bem como qualificar os serviços prestados, a partir de reflexões e proposições das ações empreendidas no atendimento aos usuários do SUS.

Desta forma, as discussões advindas dos artigos estão dialeticamente imbricadas com fatores intrínsecos e extrínsecos ao Serviço Social, corroborando diretamente com a formação profissional. No que tange aos fatores extrínsecos, denota-se que os artigos refletem questões que tangenciam tanto a política de saúde, como o cotidiano do hospital, contribuindo diretamente para ampliar as reflexões sobre a processualidade da SUS na realidade do HC/UFG, articulados à conjuntura atual.

No que se refere aos aspectos intrínsecos ao Serviço Social, é possível destacar que essas reflexões possibilitam tanto revisitar a atuação profissional dos assistentes sociais no HC/UFG, quanto ampliar as discussões da categoria profissional nos diversos espaços de construção coletiva, com ênfase à formação profissional, na perspectiva da afirmação do projeto ético-político.

Vale ressaltar que, embora a residência multiprofissional seja definida como modalidade de ensino de pós-graduação lato sensu, voltada para a educação em serviço, foi adotada, em sua maioria, a modalidade de pesquisa bibliográfica e documental. Apenas um trabalho realizou pesquisa de campo e dois utilizaram além da pesquisa documental, a observação participante. Reconhece-se a importância da pesquisa de campo para o processo de construção do saber, sobretudo ao Serviço Social -, uma profisssão que atingiu sua maturidade enquanto área de conhecimento, acima de tudo diante das produções advindas das pesquisas realizadas. Para os limites dessa pesquisa realizada, é possível inferir em relação à pesquisa de campo enquanto um desafio a ser superado frente à possibilidade de construção do conhecimento tanto intrínseco ao Serviço Social, como para a área da saúde.

Tais evidências denotam limites e possibilidades que devem ser descortinados em pesquisa de natureza qualitativa, que possam abranger a pesquisa de campo, posto há limites relativos à própria característica da pesquisa desenvolvida a partir do Estado da Arte, não sendo objetivo da mesma identificar tais questões. Os limites e possibilidades postos por esta evidência deverão, contudo, ser descortinados em pesquisas futuras, em razão dos limites da própria característica da pesquisa desenvolvida a partir do Estado da Arte.

Seguindo nas questões metodológicas, é possível perceber que a maioria dos trabalhos utilizou, como fonte de pesquisa bibliográfica, obras da biblioteca básica do Serviço Social (à exceção de dois). A pesquisa social requer a explícita indicação do método utilizado para a análise, sendo fundamental ter clareza de que não é possível recortar um objeto de estudo e desvinculá-lo da realidade social, de maneira a-histórica. Todo fenômeno é cunhado pelas condições históricas e só pode ser compreendido no seu movimento e em sua relação com a totalidade. Nos trabalhos analisados, o método não foi explicitado em grande parte deles, o que pode comprometer o trabalho. Não sua explicitação em si, mas sua a apropriação na elaboração do trabalho, posto que concordamos com Yazbek (2009, p. 147): “método é, pois a trajetória teórica, o movimento teórico que se observa na explicação sobre o ser social. É o posicionamento do sujeito que investiga face ao investigado". Nesse sentido, o método possibilita um padrão de construção intelectual na explicação de aproximações sucessivas à realidade, a partir da teoria utilizada.

A análise desse aspecto evidenciou, por um lado, produções que demonstram uma visão crítica do objeto, relacionando-o de forma mais abrangente à totalidade social e as contradições inerentes à sociedade capitalista com destaque para a questão social, o Estado capitalista e políticas públicas, especialmente a saúde; por outro lado, alguns trabalhos apresentam análises frágeis e focalistas, primadas pela descrição da atuação profissional, 
dos espaços sócio-ocupacionais ou do perfil dos usuários, sem, contudo, fazer uma articulação aos referenciais teóricos do Serviço Social; o que pode comprometer a análise crítica do trabalho na perspectiva da totalidade.

Todavia, os limites e contradições presentes nos trabalhos espelham os impasses vivenciados pelo Serviço Social brasileiro, que se colocam como entraves para a consolidação do Projeto ético-político, agravado pela conjuntura de ajustes fiscais e retração dos direitos que refletem, principalmente na política de saúde, na má qualidade dos serviços prestados, na falta de profissionais especializados e de medicamentos necessários, nas dificuldades de acesso, nas demandas reprimidas, na precariedade das instituições de saúde, com equipamentos obsoletos, no desvio e insuficiência de recursos e nos traços de improvisação. Desta feita, repercutindo no trabalho do assistente social, com prevalência da rotina burocrática e imediatista, do atendimento individual e fragmentado para suprir os interesses institucionais, comprometendo o trato crítico e qualificado às demandas sociais e profissionais da contemporaneidade.

É fundamental, como diz Iamamoto (2000, p. 20), ampliar as dimensões, os horizontes da profissão "romper com uma visão endógena. Extrapolar o Serviço Social para melhor apreendê-lo na história da sociedade da qual ele é parte e expressão". Assim, torna-se imprescindível para a apreensão das mediações que permeiam a realidade social, lócus do fazer profissional, uma abordagem crítica e reflexiva. Destaca-se que o eixo fundamental para a intervenção profissional, para o seu desenvolvimento, é a apreensão dessa realidade que deve pautar-se em uma análise crítica.

Depreende-se que o exercício profissional, bem como sua análise, deve ir além do imediatismo, da atividade burocrática e das rotinas institucionais, apreendendo o movimento da realidade. Para tanto, o domínio teórico-crítico e ético-político é fundamental para a leitura da realidade social, e dos processos profissionais; articulando as dimensões constitutivas da profissão. Sobretudo no contexto atual, em que se intensifica a hegemonia da lógica financeira do regime de acumulação, em que as antinomias se apresentam com grande volatilidade do crescimento econômico expressando maior concentração de renda e de pobreza.

Além destes aspectos, vale ressaltar que há um redimensionamento radical nas relações entre Estado e Sociedade, evidenciam-se medidas de redução, cada vez maior do Estado - a serviço dos interesses privados, vive-se a "sociedade do mercado", que passa a ser regulador da vida social. Aqui se localiza uma questão central para a discussão em pauta: a tensão entre a defesa dos direitos sociais e a mercantilização do atendimento às necessidades de toda a sociedade, aspecto esse abordado em vários trabalhos analisados.

É possível reconhecer como outro grande desafio à intervenção profissional, e neste caso, à Residência Multiprofissional, o de lidar com as novas facetas e artimanhas do capitalismo - novos mecanismos de reprodução expressos na mundialização do capital. Essa lógica também se expressa na questão dos direitos e nas reivindicações de frações da sociedade, de suas organizações privadas. Daí a importância da inserção, cada vez maior, do Serviço Social em experiências de Residência Multiprofissional em Saúde, pois garante-se dessa forma, o processo de formação continuada da profissão e contribui com o processo de reflexão crítica acerca da realidade social proporcionando assim, um momento fecundo de atualização, produção e avaliação coletiva. Ressalta-se ainda, a necessidade de, cada vez mais, consolidar espaços de formação e capacitação de profissionais da saúde, que propiciem a interlocução e a qualificação do diálogo entre os diversos sujeitos que atuam nessa importante política pública.

\section{Considerações finais}

A residência multiprofissional em saúde se constitui como uma das estratégias de formação profissional na consolidação da política de educação em saúde para o SUS. Esse processo de formação consolidado a partir da Residência aprofunda e reafirma os princípios da universalidade e da concepção ampliada de saúde e de profissão, constituindo-se em importante estratégia para as profissões, para a defesa da política pública de saúde, numa perspectiva democrática e qualificada, reafirmando ainda a defesa da qualidade dos serviços prestados a partir do princípio da qualificação das equipes que atuam no âmbito da saúde; rompendo com a perspectiva tecnicista na medida em que valoriza o saber-fazer em sua articulação dialética da relação teoria e prática.

Ao constituir a fundamentação teórica, base de intervenção profissional é como sujeito histórico que a profissão se coloca, nas relações estabelecidas com os diversos sujeitos sociais e nas contradições inerentes a uma sociedade antagônica onde a luta de classes efetiva-se, daí a importância de consolidar um trabalho que prime pela dimensão político-pedagógica em seu atendimento cotidiano, desvelando a correlação de forças, bem como, a forma em que os homens vão tecendo o quadro sócio-político, econômico e cultural, ao descortinar as relações consolidadas pela sociabilidade burguesa.

A proposta pedagógica que vem sendo construída na residência multiprofissional instaura-se nesse processo, em um percurso que compõe o movimento da realidade partindo das reais condições de vida humana e as formas conjunturais que o constrói. Para isto, é necessário encarar o concreto como totalidade 
partindo de sua relação com as particularidades e singularidades da expressão cotidiana da realidade. Ao considerar essa relação consolida-se uma abordagem que não se restringe ao campo privado, mas vinculase a uma racionalidade histórica e social. Isto implica considerar ainda que um determinado modo de vida expressa como se dá a reprodução de um processo social. E é a partir desses elementos que vem se efetivando o projeto ético-político profissional.

O processo educativo, como articulador nas profissões que integram essa proposta, contribui para fortalecer a autonomia profissional do assistente social, bem como impulsiona a superação da subalternidade histórica imposta pelo cotidiano profissional na área da saúde, contribuindo ainda para a "quebra" da hegemonia do "saber médico" nesses espaços sócio-ocupacionais, e viabilizam o trabalho numa perspectiva criadora, no sentido de que não existe uma realidade em si e por si, mas apenas em relação histórica com os homens que a modificam (GRAMSCI, 1978). Nesse entendimento, considera-se, enquanto um dos pontos fundamentais a sistematização elaborada no final da residência, concretizada nos TCCs - contribuindo significativamente para o Programa de Residência, para a área da saúde, e sobretudo para o Serviço Social, à luz dos referenciais que norteiam a profissão.

Um elemento a ser destacado refere-se à necessidade de reafirmação e fortalecimento do projeto éticopolítico como aporte às análises empreendidas na residência processo esse que só se constitui com a capacidade teórico-crítica mencionada. Vale ressaltar que a dimensão da interdisciplinaridade preconizada na proposta da Residência Multiprofissional coaduna-se com o princípio do pluralismo profissional presente no Código de Ética Profissional, bem como nas diretrizes curriculares de 1996, entendida pelo reconhecimento de diferentes concepções e leituras, tanto no que se refere à realidade social quanto à profissão e o que a particulariza, inserida em um processo de disputa pela hegemonia, no confronto de forças diferentes no que se refere ao entendimento da sociedade e de seus projetos. Esse aspecto também merece ser considerado nos trabalhos finais.

Na sistematização da pesquisa, é possível afirmar a prevalência da temática da política de saúde. Parte dos trabalhos relaciona este tema à dificuldade de acesso, precariedade dos serviços e humanização. Neles, o enfoque central é dado aos limites da efetivação para a concretização como direito, tal como definido na Constituição Federal de 1988. Outro conjunto de trabalhos toma como objeto de reflexão a prática do assistente social refletindo positivamente tanto para o Programa de Residência do HC-UFG/EBSERH, quanto para a categoria profissional de assistentes sociais.

Nesse contexto, as reflexões dos residentes dão destaque à conjuntura atual de regressão dos direitos sociais que focaliza o atendimento das demandas sociais no campo do não direito, desencadeando em grandes desafios e implicações para o trabalho do assistente social. De acordo com o Conselho Federal de Serviço Social - CFESS (2010, p. 65), "Os assistentes sociais, nas suas diversas inserções e

compreender as produções realizadas no interior dos Programas de Residência Multiprofissional em saúde é uma das alternativas para revisitar e analisar criticamente a atuação profissional ... na efetivação das suas atribuições e competências, precisam ter como preocupação as diversas armadilhas que são colocadas pela organização social capitalista e pelas teorias não críticas e pós-modernas no que se refere à análise das expressões da questão social evidenciadas no cotidiano profissional".

Frente aos desafios e entraves, o assistente social na saúde deve identificar as mediações e possibilidades dadas pela realidade social que engloba as relações entre a instituição e o usuário, as demandas institucionais, profissionais e da população usuária dos serviços de saúde, tendo em vista a sua participação como sujeito ao acessar direitos e serviços, bem como em questões que interferem no processo saúde e doença. Para tanto, faz-se necessário o fortalecimento do Projeto ético-político profissional no cotidiano do trabalho do assistente social, assumindo um compromisso com a qualificação profissional permanente que possibilita romper com as amarras do cotidiano, desatando os nós para a compreensão da realidade apresentada em seus desafios e possibilidades.

Nesse descortinamento, compreender as produções realizadas no interior dos Programas de Residência Multiprofissional em saúde é uma das alternativas para revisitar e analisar criticamente a atuação profissional, decorrendo em contribuições intrínsecas e extrínsecas ao Serviço Social, bem como à possibilidade de alteração dos serviços prestados à população usuária na área da saúde com vistas à qualidade dos mesmos em consonância com as lutas e mobilizações galgados pelo Movimento de Reforma Sanitária e referendados pelos princípios do SUS. 


\section{Referências}

BRASIL. Lei 11.129 de 30 de junho de 2005. Institui o Programa Nacional de Inclusão de Jovens - ProJovem; cria o Conselho Nacional da Juventude - CNJ e a Secretaria Nacional de Juventude; altera as Leis ns. 10.683, de 28 de maio de 2003, e 10.429, de 24 de abril de 2002; e dá outras providências. Disponível em: <http://www.planalto.gov.br/ccivil_03/_Ato2004-2006/2005/Lei/L11129.htm>. Acesso em: 10 nov. 2016.

CONSELHO FEDERAL DE SERVIÇO SOCIAL. Parâmetros para atuação de Assistentes Sociais na saúde. Brasília: CFESS, 2010. Disponível em: <http://www.cfess.org.br/arquivos/Parametros_para_a_Atuacao_de_Assistentes_Sociais_na_Saude.pdf >. Acesso em: 14 nov. 2016.

FERREIRA, N. S. A. As pesquisas denominadas "estado da arte". Educação \& Sociedade, ano XXIII, n. 79, p. 257-272, ago. 2002. GRAMSCI, A. A concepção dialética da história. Rio de Janeiro: Civilização Brasileira, 1978.

IAMAMOTO, M. V. O Serviço Social na contemporaneidade: trabalho e formação profissional. São Paulo: Cortez, 2000.

MENDES, A. G. Residência Multiprofissional em Saúde e Serviço Social. In: SILVA, L. B.; RAMOS, A. (Orgs.). Serviço Social, Saúde e Questões Contemporâneas: reflexões críticas sobre a prática profissional. Campinas, SP: Papel Social, 2013.

MENDES, A. G.; SILVA, L. B. Serviço Social, Saúde e a Interdisciplinaridade: algumas questões para o debate. In: SILVA, L. B.; RAMOS, A. (Orgs.). Serviço Social, Saúde e Questões Contemporâneas: reflexões críticas sobre a prática profissional. Campinas, SP: Papel Social, 2013. p. 49-64.

VASCONCELOS, A. M. A prática do Serviço Social. Cotidiano, formação e alternativas na área da saúde. São Paulo: Cortez, 2003.

YAZBEK, M. C. Fundamentos históricos e teórico-metodológicos do Serviço Social. In: CONSELHO FEDERAL DE SERVIÇO SOCIAL. Serviço Social: direitos e competências profissionais. Brasília: CFESS, 2009. p. 143-164.

\section{Notas}

1 Destas, apenas uma nãoé em Serviço Social.

2 Foi constato que, desde 2010, foram admitidas por meio da seleção 24 profissionais do Serviço Social para a Residência Multiprofissional, destes quatro desistiram, dezoito concluíram, mas dois não entregaram o trabalho final e três trabalhos não foram localizados.

\section{Denise Carmen Andrade Neves}

denise.andradeneves@gmail.com

Doutorado em Serviço Social pela Universidade Federal do Rio de Janeiro (UFRJ)

Professora de Serviço Social da Pontifícia Universidade Católica de Goiás (PUC/GO)

\section{PUC/GO}

Av. Universitária, 1440 - Setor Universitário

Goiânia - Goiás - Brasil

CEP: 74.605-010

\section{Tereza Cristina Pires Favaro}

cristina_gyn@hotmail.com

Doutora em História pela Universidade Federal de Goiás (UFG)

Professora da Residência Multiprofissional em Saúde do HC (UFG/EBSERH)

\section{HC-UFG/EBSERH}

$1^{a}$ Av. s/n., Setor Leste Universitário

Goiânia - Goiás - Brasil

CEP: 74.605-020

\section{Carla Ágda Gonçalves}

carlaagdaufg@gmail.com

Doutora em Serviço Social pela Pontifícia Universidade Católica de São Paulo (PUC/SP)

Professora de Serviço Social da Universidade Federal de Goiás (UFG/Regional Goiás)

Professora da Residência Multiprofissional em Saúde do HC (UFG/EBSERH) 


\section{UFG/ Regional Goiás}

Av. Bom Pastor, s/n. - Bairro Areião

Cidade de Goiás - Goiás - Brasil

CEP: 76.600-000 